genic model Fisher's heuristic vision is upheld.

In my own view the bizarre, the exaggerated, the seemingly arbitrary in animal ornament speaks strongly for the idea of positive feedback processes occurring at least sporadically, but the point that such feedback can't occur if fighting rules and real choice is absent shows the intra-sex competition must be able to produce highly bizarre weapons and displays on its own. In other words, facts suggest what theory can confirm - it pays to advertise, by some striking possession, your strength if you have it. Otherwise you may waste energy and even gore in proving your superiority to lesser rivals. This point is not well brought out in any of the papers, even though it helps in explaining much that might otherwise suggest the "runaway" selection process. A further point is that to look for winners of combats is exactly what females should do if they sought for their species a moderate alternative to the dangerous dysgenics of the Fisher, Lande and Kirkpatrick process. Perhaps we tend to see around us mainly the species that took this route and survived - well bred and forewarned, so to speak, they are species that on seeing deadly Preference on the road hasten by on the other side.

Now to the third question. Why should the female (as it usually is), the hitch-hiker yet unthought of, ever start seeking anything like all this? Here, most of the authors are rather against the possibility of a large supply of unfixed good genes of utilitarian purpose. Some, however, for example Arnold, readily pre-suppose an undiminishing supply of the Fisher-Lande character genes, arguing like Lande that this supply can be as constantly topped up by mutation as it is depleted by the sexual selection. A few authors invoke a similar mutational maintenance of variance for utilitarian characters. But in my opinion this support is still inadequate to the case. For the whole crazy sexual carnival to make sense, a large and essentially undepletable utilitarian variance needs to be there. Such variance, 1 believe, may be reasonably derived from genetic disease and parasite resistance genes that are kept moving in slow dynamic polymorphism by LotkaVolterra-type frequency-dependent processes.

In 1975, Zahavi also suggested a persistent utilitarian function for sexual selection and tied it in with a seemingly perverse notion that selectors are looking for physical handicaps that prove the potential mate's vigour. This idea gets short shrift in the book. Only three of the more theoretical writers even throw a nod towards it, all of them quizzically at that. Although it was carelessly presented, I believe that Zahavi's general notion is sustainable. Attacks on the letter of what he said were justified, but sympathy to a good half of the idea would have been justified too. Dominey has already neatly shown that the concepts of Fisher and Zahavi are not as mutually exclusive as most authors, Zahavi included, seem to assume. I find it hard to believe that whole groups like pheasants and birds of paradise have evolved and speciated successfully if their extraordinary sexual proceedings gain nothing for the participants except the plumes and wattles and super-long coiled tracheae, all of which seem so totally arbitrary, indeed deleterious for coping with the challenges of life in general. While not denying the potential for arbitrariness and exaggeration latent in gene-inspired choosing, utilitarian "good genes" as the original or ultimate objective of choice surely must exist.

Other small criticisms of the book concern lines of thought ignored to even worse degree than Zahavi's. But the first gripe is that it is hard to find out what has been overlooked because there is no author index. One's first use of such an index is, admittedly, almost always vanity; but even so author indexes are valuable, especially when the reference lists are separated at the end of each chapter as here. What I did still not find, even after thumbing the separate lists, was reference to the considerable statistical literature on stopping rules in sequential searches (e.g. Am. Stat. Assoc.

J., March 1966). It was especially surprising to find no reference to this mathematical line of ideas even in Parker's original and useful chapter on mating decisions. Titles used in the literature "The Dowry Problem", "The Beauty Contest" etc. - should alert mate-choice biologists, one would think. But perhaps a third title, "The Secretary Problem", hints at the reason for disinterest - too few biologists are in a position to be interviewing secretaries with a view to marrying the richest and prettiest.

My second and quite different criticism is that I could find no reference to disease contagion, venereal or otherwise, as a factor in mate choice. Freeland's (Biotropica 8, 12 ; 1976) discussion of this for primates is never mentioned, although a little charted sea may stretch out from here.

As corrective to these complaints, let it be said that many important topics are covered that are not mentioned in this review. Altogether the book is a well-made informative heap and every biologist at play in the meadow of its gathering, and others too, will want to climb on it.

W.D. Hamilton is Professor of Evolutionary Biology at the Museum of Zoology, University of Michigan, Ann Arbor.

\section{Balance of power}

\section{Ian Smart}

\section{Energy: A Guidebook.}

By Janet Ramage.

Oxford University Press: 1983.

Pp.345. Hbk £15; pbk £5.95, \$12.95.

DR Ramage sets out to provide a comprehensive, balanced guide to all the most important features of the energy world, present and future, in terms intelligible to a reader with no technical background. She does not, of course, succeed. Within this extent, no one could. But she makes an absorbing effort. After briefly reviewing contemporary energy use, with 1980 as her focal year, she devotes more than half of her text to explaining the available technologies of energy conversion. A final section of the book then discusses the problems of foreseeing and planning for the future, while also allowing the author to tidy up some loose ends by importing a rather sketchy chapter on conservation and one or two additional supply and conversion options such as hydrogen and biogas.

Comprehensive, the book is not. Dr Ramage is most obviously enthusiastic, and splendidly lucid, when writing about the generation and use of electricity. Energy for transport, space heating and lighting receives rather less attention. And there is very little indeed about industrial process heat - which may help to account for the fact that the chapter on oil and natural gas deals almost exclusively with motor vehicles. More seriously, the author's continual and often enlightening emphasis on efficiency is confined within the engineer's meaning of the term. Questions of economic cost and benefit are hardly mentioned, let alone addressed.

Intelligible, it is. Dr Ramage has been at great pains to explain the rudiments of both science and technology in simple terms. The lay reader may still have to work hard at times to apprehend a dense exposition, but the evidence is all here. Balanced, it also is - but at a price. Dr Ramage is scrupulous in setting out conflicting arguments, and extraordinarily discreet about her own conclusions. Inevitably, that will leave many of her readers dissatisfied. She tells them what to think about, but not what to think. Indeed, she deliberately obstructs any simple conviction about future policy, by insisting at every point on the complexity of the choices to be made and the uncertainty about their implications.

This is, in fact, a simple book that enormously complicates the subject it discusses. Such an inversion of the prevailing fashion is not the least of its attractions. And an author who writes " we shouldn't be fooled in to believing that any number of pages of mathematics can produce reliable predictions from uncertain data and doubtful assumptions" (p.282) has at least one reader on her side.

Ian Smart is an independent adviser on international energy affairs and the secretary of the British Institute of Energy Economics. 